\title{
Antibiotic Resistance in Campylobacter Isolated from Patients with Gastroenteritis in a Teaching Hospital in Ghana
}

\author{
Akosua B. Karikari1 ${ }^{*}$, Kwasi Obiri-Danso², Enoch H. Frimpong3, Karen A. Krogfelt ${ }^{4}$ \\ ${ }^{1}$ Department of Clinical Microbiology, University for Development Studies, Tamale, Ghana \\ ${ }^{2}$ Department of Theoretical and Applied Biology, Kwame Nkrumah University of Science and Technology, Kumasi, Ghana \\ ${ }^{3}$ Department of Clinical Microbiology, Kwame Nkrumah University of Science and Technology, Kumasi, Ghana \\ ${ }^{4}$ Department of Microbiology \& Infection Control, Statens Serum Institute, Copenhagen, Denmark \\ Email:*asbuks@yahoo.co.uk
}

How to cite this paper: Karikari, A.B., Obiri-Danso, K., Frimpong, E.H. and Krogfelt, K.A. (2017) Antibiotic Resistance in Campylobacter Isolated from Patients with Gastroenteritis in a Teaching Hospital in Ghana. Open Journal of Medical Microbiology, 7, 1-11.

https://doi.org/10.4236/ojmm.2017.71001

Received: December 11, 2016

Accepted: February 3, 2017

Published: February 6, 2017

Copyright $\odot 2017$ by authors and Scientific Research Publishing Inc. This work is licensed under the Creative Commons Attribution International License (CC BY 4.0).

http://creativecommons.org/licenses/by/4.0/

\begin{abstract}
Campylobacter is a leading causal agent of bacterial enteritis worldwide, but its prevalence is not well documented in Ghanaian hospitals. This study isolated Campylobacter species from patients with enteritis or urinary tract infections attending Komfo Anokye Teaching Hospital and assessed the antibiogram profile of isolated species. Two hundred and two (202) in-patients and outpatients samples of all age groups diagnosed with enteritis or UTI infections were analyzed from May 2013 to August 2013. Campylobacter species were detected using selective agar (mCCDA) and confirmed on API Campy system (bioMérieux, France), with disk diffusion method determined the resistance profile of the species. Of the 128 enteritis and 74 UTI patients samples analyzed, 26 and 9 isolates were respectively confirmed as Campylobacter spp. giving a prevalence of $17.3 \%$ (35/202). Species identified were C. jejuni (40\%), C. jejuni sub sp. doylei (2.8\%), C. coli (37\%) and C. lari (20\%). Resistance was $92.3 \%-100 \%$ each to erythromycin and the $\beta$-lactams, $61.5 \%-86.7 \%$ to trimethoprim sulfamethoxazole, $92.3 \%-93.3 \%$ to tetracycline, $46.2 \%-80 \%$ to chloramphenicol, $0 \%-60 \%$ to aminoglycosides and $0 \%$ to imipenem. Multidrug resistance of $97.1 \%$ was detected among species. Empirical treatment of Campylobacter enteritis with erythromycin and other common and cheap drugs may result in treatment failure in the face of high level resistance observed among the Campylobacter species.
\end{abstract}

\section{Keywords}

Campylobacter, Antibiotic Resistance, Gastroenteritis, KATH, Ghana 


\section{Introduction}

Campylobacter is a major agent of gastroenteritis worldwide, and in developing countries infection has strikingly increased in recent years [1] [2]. Worldwide, Campylobacter causes between 400 - 500 million cases of diarrhea each year [3]. Campylobacter jejuni (sub sp. jejuni and doylei) and C. coli have mostly been implicated in human infections as $C$. lari and $C$. upsaliensis are less prevalent [4]. Campylobacteriosis is usually mild and self-limiting, but uncommonly associated with infections such as endocarditis, septicaemia, cholecystitis and urinary tract infections [5] [6]. These infections typically warrant treatment as well as infections of the immunosuppressed, pregnant women, children, elderly and those with recurrent symptoms; in such cases the macrolides and fluoroquinolones are the first line drugs prescribed [7] [8]. However, global reports of increasing resistance of Campylobacter to the drugs of choice and other clinically important antibiotics from human and animal origin are well established [3] [9] [10]. The resistance situation in developing countries such as Ghana might become worse as a result of widespread and unrestricted use of antibiotics as well as inadequate research into antimicrobial resistance.

In Ghana, diarrhea has been identified as the second most common health problem treated in outpatient clinics [11]. Routine screening of aetiological agents of diarrhea currently does not include Campylobacter as evident in the many hospital records in Ghana. In the proper management of diarrhea, a key agent such as Campylobacter cannot be ignored. This study reported on the prevalence of Campylobacter infections among patients presenting with gastric infections and the resistance profile of isolated species.

\section{Materials and Method}

\section{Study population and site}

This study was undertaken at the Microbiology Laboratory of the Komfo Anokye Teaching Hospital (KATH), Kumasi. The hospital is the second-largest in Ghana and the only tertiary health institution in the Ashanti Region. It is a 1, 200 bed capacity referral hospital for 8 Regions in Ghana. In-patients at the various wards and out patients of KATH who were diagnosed with gastroenteritis or urinary tract infections (UTI) were enrolled in the study from May 2013 to August 2013. Patients of all age groups were recruited.

\section{Sample processing, isolation and identification}

Stool and mid-stream urine specimens submitted to the Microbiology Laboratory for bacteriological analysis were processed to obtain our target organism. A loopful of fresh faeces and $0.001 \mathrm{~mL}$ of urine were plated directly onto modified charcoal-cefoperazone-deoxycholate agar (mCCDA Oxoid CM0689) supplemented with CCDA selective supplement (Oxoid, SRO155E) using sterile loop and 0.001 calibrated loop respectively. The plates were kept in a $2.5 \mathrm{~L}$ anaerobic jar and Campy-Gen gas generating kit (Oxoid CN0025A) introduced to keep the microaerophilic condition at $42^{\circ} \mathrm{C}$ for 48 hours. Campylobacter species were identified by morphological characteristics and biochemically by Gram 
stain, catalase and oxidase test. Colonies that were small curved Gram negative, oxidase and catalase positive were further analysed on API Campy to identify to species level (bioMérieux, France).

\section{Antimicrobial Susceptibility test}

Antimicrobial susceptibility test was performed by the disk diffusion method on Mueller-Hinton agar (Liofilchem-Italy) supplemented with 5\% sheep blood; inoculated with $0.5 \mathrm{McF}$ arland suspension and incubated under microaerophilic condition using Campy-Gen $\mathrm{CO}_{2}$ generating kit at $42^{\circ} \mathrm{C}$ for 24 hours [12]. Essayed antibiotics sourced from Rosco (Neo-Sensitabs ${ }^{\mathrm{TM}}$, Denmark) included: Ampicillin (10 $\mu \mathrm{g} / \mathrm{disc})$, chloramphenicol (30 $\mu \mathrm{g} / \mathrm{disc})$, ciprofloxacin $(5 \mu \mathrm{g} / \mathrm{disc})$, kanamycin $(30 \mu \mathrm{g} / \mathrm{disc})$, erythromycin $(15 \mu \mathrm{g} / \mathrm{disc})$, gentamicin $(10 \mu \mathrm{g} / \mathrm{disc})$, nalidixic acid $(30 \mu \mathrm{g} / \mathrm{disc})$, tetracycline $(30 \mu \mathrm{g} / \mathrm{disc})$, cephalexin $(30 \mu \mathrm{g} / \mathrm{disc})$, trimethoprim sulfamethoxazole ( $25 \mu \mathrm{g} / \mathrm{disc})$, norfloxacin $(10 \mu \mathrm{g} / \mathrm{disc})$, cefotaxime $(30 \mu \mathrm{g} / \mathrm{disc})$ and imipenem $(10 \mu \mathrm{g} / \mathrm{disc})$. The diameter of inhibition zone sizes were measured and interpreted according to EUCAST- and CLSI 2013 breakpoints. Established breakpoints for enterobacteriaceae were used to interpret the results of norfloxacin, trimethoprim sulfamethoxazole, cefotaxime and kanamycin as CLSI Campylobacter breakpoints for these antibiotics has not yet been established. Quality control was achieved using E. coli (ATCC25922) and S. aureus (ATCC25923) strains.

\section{Data Analysis}

Descriptive analysis was carried out using percentages. Associations were determined using the Chi-square test at a significance level of $<0.05$. All statistical tests were two-tailed. Stata 14.0 software was used for statistical analysis.

\section{Ethical Approval}

Ethical clearance was obtained from the joint Committee on Human Research Publications and Ethics of the School of Medical Sciences and the Komfo Anokye Teaching Hospital (CHRPE/RC/066/14). Specimens collected and processed were given codes; all identities on samples were removed, which made the patients anonymous.

\section{Results}

\section{Isolation rate of Campylobacter from patients with UTI and enteritis}

Of the 128 enteritis and 74 UTI cases, $26(20.3 \%)$ and $9(12.2 \%)$ isolates were respectively confirmed as Campylobacter spp. giving a prevalence of $17.3 \%$ (Table 1). No significant difference was observed in the isolation rate of Campylobacter from enteritis and UTI infections $(\mathrm{p}=0.1403)$. All the Campylobacter

Table 1. Isolation rate of Campylobacter from patients with UTI and enteritis.

\begin{tabular}{cccc}
\hline Infection & No. samples & No. isolates identified & p-value \\
\hline Enteritis & 128 & $26(20.3)$ & 0.140 \\
UTI & 74 & $9(12.2)$ & \\
Total & 202 & $35(17.3)$ & \\
\hline
\end{tabular}


species from enteritis were isolated from patients at the out-patient department (OPD), while 4 of the patients in the ward and 5 from the OPD UTI cases were positive for Campylobacter. About $88 \%(31 / 35)$ of cases came from the OPD and $11.4 \%(4 / 35)$ from the Wards.

Species specific prevalence of Campylobacter from patients with UTI and enteritis

Campylobacter coli $(46.2 \%)$ were the dominant species recovered from enteritis followed by $C$. jejuni (38.5\%) and $C$. lari (11.5\%) but $44.4 \%$ C. jejuni, $44.4 \%$ C. lari and $11.1 \%$ C. coli were recovered from UTI infections. One (1) C. jejuni sub sp. doylei was obtained from enteritis but none was found in UTI infections (Table 2).

\section{Demographic distribution of Campylobacter infections}

Isolation rate of Campylobacter was highest in the 10 - 29 (34.3\%) age group, followed by 30 - 49 (28.6\%) and 0 - 9 (22.8.0\%) with age group above 50 recording the least (14.3\%). The proportion of female and male patients was $67.6 \%$ and $32.4 \%$ respectively.

\section{Antibiotic resistance profiles of Campylobacter species from patients}

Resistance among isolates from enteritis to the beta-lactams (Ampicillin, cefotaxime and cephalexin) was $96 \%$ - 100\%; as $96 \%$ was to erythromycin, $92 \%$ to tetracycline, $81 \%$ to trimethoprim sulfamethoxazole and $54 \%$ to chloramphenicol. Against the quinolones resistance was $23 \%$ each to nalidixic acid and norfloxacin and $35 \%$ to ciprofloxacin. Resistance to the aminoglycosides was $42 \%$ to gentamicin and $8 \%$ to kanamycin. Resistance among UTI isolates to the beta-lactams, erythromycin and tetracycline was $100 \%$ each, $67 \%$ to trimethoprim sulfamethoxazole and $56 \%$ to chloramphenicol. Against the quinolones, resistance was $67 \%$ each to nalidixic acid, norfloxacin and ciprofloxacin as $44 \%$ and $11 \%$ was observed respectively against gentamicinand kanamycin. All isolates exhibited $0 \%$ resistance to imipenem (Table 3 ). The difference in resistance levels between enteritis and UTI isolates was highly significant $(\mathrm{p}<0.0001)$.

Table 2. Campylobacter spp. isolated from patients with UTI and enteritis.

\begin{tabular}{ccc}
\hline Species & No. isolates & Percentage (\%) \\
\hline Enteritis $\mathbf{n}=\mathbf{2 6}$ & 10 & 38.5 \\
\hline C. jejuni & 1 & 3.8 \\
C. jejuni sub. sp. doylei & 12 & 46.2 \\
C. coli & 3 & 11.5 \\
C. lari & & \\
\hline UTI $\mathbf{n}=\mathbf{9}$ & 4 & 44.4 \\
\hline C. jejuni & 0 & 0 \\
C. jejuni sub. sp. doylei & 1 & 11.1 \\
C. coli & 4 & 44.4 \\
\hline C. lari & & \\
\hline
\end{tabular}




\section{Resistance profile of $C$. jejuni and $C$. coli isolates from patients}

Resistance among $C$. jejuni strains to the $\beta$-lactams and erythromycin was $100 \%$ each, to the quinolones, $33.3 \%-46.7 \%$, to the aminoglycosides $13.3 \%$ $60 \%, 93.3 \%$ to tetracycline, $80 \%$ to chloramphenicol and $86.7 \%$ to trimethoprim sulfamethoxazole. Strains of C. coli showed resistance of $92.3 \%-100 \%$ to the $\beta$ lactams and erythromycin, $0 \%-23 \%$ to the quinolones and aminoglycosides, $92.3 \%$ to tetracycline, $46.2 \%$ to chloramphenicol and $61.5 \%$ to trimethoprim sulfamethoxazole. No resistance was observed among $C$. coli strains to nalidixic acid, norfloxacin and kanamycin. All strains of $C$. jejuni and $C$. coli were sensitive to imipenem. Generally resistance was common among $C$. jejuni strains than $C$. coli and the difference was significant, $\mathrm{p}<0.0001$ (Table 4).

Table 3. Antibiotic resistance profile of Campylobacter spp. recovered from patients with UTI and enteritis.

\begin{tabular}{|c|c|c|c|c|}
\hline \multicolumn{5}{|c|}{ Percentage Resistance } \\
\hline Antibiotic & Species Identified $\mathrm{N}=35$ & Enteritis $\mathrm{N}=26$ & UTI N $=9$ & p-value $<0.0001$ \\
\hline Nalidixic acid & 40 & 23 & 67 & \\
\hline Norfloxacin & 34 & 23 & 67 & \\
\hline Ciprofloxacin & 46 & 35 & 78 & \\
\hline Ampicillin & 97 & 96 & 100 & \\
\hline Cefotaxime & 100 & 100 & 100 & \\
\hline Cephalexin & 97 & 96 & 100 & \\
\hline Kanamycin & 9 & 8 & 11 & \\
\hline Gentamicin & 43 & 42 & 44 & \\
\hline Erythromycin & 97 & 96 & 100 & \\
\hline Tetracycline & 94 & 92 & 100 & \\
\hline Chloramphenicol & 54 & 54 & 56 & \\
\hline SXT & 77 & 81 & 67 & \\
\hline
\end{tabular}

SXT $=$ Trimethoprim sulfamethoxazole.

Table 4. Resistance profile of $C$. jejuni and C. coli species.

\begin{tabular}{|c|c|c|c|}
\hline Antibiotic & C. jejuni $\mathrm{N}=15$ & C. $\operatorname{coli} \mathrm{N}=13$ & p-value $<0.0001$ \\
\hline Nalidixic acid & 33.3 & 0 & \\
\hline Norfloxacin & 46.7 & 0 & \\
\hline Ciprofloxacin & 40 & 23 & \\
\hline Ampicillin & 100 & 92.3 & \\
\hline Cefotaxime & 100 & 100 & \\
\hline Cephalexin & 100 & 92.3 & \\
\hline Kanamycin & 13.3 & 0 & \\
\hline Gentamicin & 60 & 23 & \\
\hline Erythromycin & 100 & 92.3 & \\
\hline Tetracycline & 93.3 & 92.3 & \\
\hline Chloramphenicol & 80 & 46.2 & \\
\hline SXT & 86.7 & 61.5 & \\
\hline
\end{tabular}

SXT = Trimethoprim sulfamethoxazole. 


\section{Multidrug resistance in Campylobacter isolates from patients}

Multidrug resistance (MDR) in this study was defined as resistance to three or more classes of antibiotics. Thirty four (34) out of the 35 Campylobacter species were multidrug resistant (97.1\%). Isolates from enteritis showed MDR of 96.3\% as $100 \%$ was observed among UTI isolates and the difference was significant; $\mathrm{p}=$ 0.0434 (Table 5).

\section{Discussion}

The $17.3 \%$ prevalence obtained in our study is within the documented range of $20 \%$ in developing countries [13] and similar to other studies in Algeria (17.7\%), Nigeria (16.5\%) and Tanzania (18.0\%) [14] [15] [16]. However, higher rates have been reported in Bangladesh (26\%), Thailand (41\%), Nigeria (62.7\%) and Ethiopia (72.7\%) [1] [2] [17] [18]. Lower rates than in our study have also been reported in Zimbabwe (9.3\%) and Egypt (5.8\% - 9\%) [10] [19]. Abraham et al. also reported $6.6 \%$ and $12.8 \%$ in studies in urban and rural Ghana [20]. Although Campylobacter is normally recovered from children less than 2 years in most developing countries [21] [22], this study rather had higher prevalence in the 21 - 30 age group [2]. This may be attributed to the design of this study which did not focus on children with acute diarrhoea and also a reflection of the infection sources which were mostly obtained from the outpatient department which is usually dominated by these age groups in the study hospital. According to Friedman et al. two age peaks occur in Campylobacter acquisition in developed nations, which are ages less thanlyear and at 15 - 55 years [23]. Secondly, Campylobacter infections were more prevalent in female (68\%) than in male (32\%) patients. In studies by Fitzgerald et al. and Friedman et al., Campylobacter was more prevalent in male patients compared to females [23] [24]. The results from this study probably speculate the gender distribution of Campylobacter infections in patients attending the Komfo Anokye Teaching hospital (KATH). Although no obvious reason has been reported on the impact of gender in Campylobacter acquisition, Gillespie et al. found that being an infant and a female has an increased risk of acquiring Campylobacter infection [25].

Campylobacter jejuni (sub species jejuni) and C. coli are the most frequently encountered species in human infections [4]. This trend was observed in this study where $80 \%$ of our isolates were identified to be C. jejuni (43\%) and C. coli (37\%) species. Similar results have also been reported in Uganda, Ethiopia and Egypt [1] [10] [26] but Gwimi et al. recovered more C. coli (60.6\%) than C. jejuni

Table 5. Multidrug resistance of Campylobacter species from patients.

\begin{tabular}{cccccc}
\hline \multicolumn{5}{c}{ Multidrug Resistance } \\
\hline Infection & & P-value & C. jejuni $=15$ & C. colin $=13$ & C. lari $=7$ \\
Enteritis & $26(96.3)$ & 0.043 & $11(42.3)$ & $12(46.2)$ & $3(11.5)$ \\
UTI & $9(100)$ & & $4(44.4)$ & $1(11.1)$ & $4(44.4)$ \\
Total & $35(97.1)$ & & & \\
\hline
\end{tabular}

Multidrug resistance defined as resistance to 3 or more classes of drugs. 
(24.5\%) from human samples in Nigeria [2]. Campylobacter lari is known to infrequently cause human diseases compared to $C$. jejuni and $C$. coli. In this study, C. lari was largely found in UTI infections (44\%) as well as patients with enteritis (11.5\%). The isolates were from adult patients with age ranging from $62-77$ years and a 3 year old child. Megraud et al. isolated urease positive $C$. lari from adult patients with diarrhoea and a child with appendicitis [27].

Resistance of species to erythromycin was alarmingly high (92.3\% - 100\%), but macrolide resistance among Campylobacter has reportedly been low and stable for a long period of time [7]; nonetheless 31\%, 51\%, and 79\% have been reported from Bulgaria, Singapore, and Nigeria, respectively [28]. Erythromycin resistance in Campylobacter has been described as gradual processes that demands prolonged exposure [8], and in agreement with this observation, Newman and colleagues have indicated that drugs such as erythromycin has been on the Ghanaian market for a relatively long period of time [29]. It is therefore reasonable to associate the high level resistance in our study to misuse and abuse of this drug due to the long exposure.

Similarly, high level resistance was observed against the $\beta$-lactams $(96 \%$ $100 \%)$ which is comparable to data from Egypt (100\%) [10]. Literature reports suggest that majority of $C$. jejuni and $C$. coli strains are intrinsically resistant to the $\beta$-lactam agents caused by the production of $\beta$-lactamases which are frequently observed [30]. It can therefore be speculated that perhaps our $C$. jejuni and $C$. coli strains were $\beta$-lactamase producing strains accounting for the high resistance.

Resistance among $C$. jejuni and $C$. coli to the quinolones was below $50 \%$ which is lower than $72 \%$ and $80 \%$ documented in Spain, Thailand and Hong Kong respectively; but comparable to rates described in Germany (41\% - 46\%), USA and Canada (19\% - 47\%) [3] [31].

Resistance to tetracycline was $92.3 \%$ - $100 \%$ but $72 \%$ has been described in Spain and a much lower rate documented in Ethiopia where tetracycline resistance of $22 \%$ has been reported in human isolates [1] [32]. Worldwide, the tetracyclines are a heavily used class of antibiotics both in human and veterinary medicine [33], and in Ghana they are largely applied in animal husbandry leading to its widespread resistance [29] [34], possibly accounting for the high resistance currently observed. All isolates were sensitive to imipenem underlining speculation that carbapenems are an exception to the general $\beta$-lactam resistance and considered to be effective also in the treatment of campylobacteriosis [3] [8]; but there is the need for caution in its use; as $17 \%$ of the isolates exhibited intermediate susceptibility. Also, the low resistance against imipenem could partly be explained by the high cost resulting in infrequent prescription and less abuse.

Multidrug resistance among our isolates was $97.1 \%$ which agrees with reports from China (90\%) but higher than rates established in France (37\%) and Korea (56\%) [35] [36] [37]. High resistance levels discovered in our study may be attributed to misuse and unwarranted prescription of antibiotics by physicians who contribute largely to the growth and spread of antibiotic resistance [38]. 
Furthermore, self-medication is a common feature of patients attending this hospital due to readily available antibiotics across the counter in pharmaceutical stores, market stalls, by the roadside and from hawkers. This practice generally leads to antibiotic under use (sub-optimal dosages) that invariably increases selective pressure and antimicrobial resistance. Macrolides and fluoroquinolones still remain the drugs of choice for Campylobacter infections in some countries, however empirical treatment of patients presenting with Campylobacter enteritis at KATH with these drugs may result in treatment failure.

\section{Conclusion}

The presence of multidrug resistant Campylobacter strains present among patients at Komfo Anokye Teaching Hospital indicates that most of the cheap and common antibiotics may not be reliable in the empirical treatment of patients with enteritis caused by Campylobacter and other related enteric pathogens and therefore necessary for laboratory confirmation of antibiotics. Nevertheless, imipenem and kanamycin proved to be highly effective. A more extensive, multi-regional study would aid in establishing the extent of Campylobacter infections in Ghana.

\section{Acknowledgements}

We thank Prof. Niels Frimodt-Møller and ADMER (www.admerproject.org) for providing funds for this study. Our appreciation also goes to Statens Serum Institute for providing control strains and the Head and staff of the Microbiology Department of Komfo Anokye Teaching Hospital.

\section{Conflict of Interest}

The authors declare that there is no conflict of interest regarding the publication of this paper.

\section{References}

[1] Ewnetu, D. and Mihret, A. (2010) Prevalence and Antimicrobial Resistance of Campylobacter Isolates from Humans and Chickens in Bahir Dar, Ethiopia. Foodborne Pathogens and Disease, 7, 667-670. https://doi.org/10.1089/fpd.2009.0433

[2] Gwimi, P.B., Faleke, O., Salihu, M.D., Magaji, A.A., Abubakar, M.B., Nwankwo, I.O., et al. (2015) Prevalence of Campylobacter Species in Faecal Samples of Pigs and Humans from Zuru Kebbi State, Nigeria. International Journal of One Health, 1, 1-5. https://doi.org/10.14202/IJOH.2015.1-5

[3] Luangtongkum, T., Jeon, B., Han, J., Plummer, P., Logue, C.M. and Zhang, Q. (2009) Antibiotic Resistance in Campylobacter: Emergence, Transmission and Persistence. Future Microbiology, 4, 189-200. https://doi.org/10.2217/17460913.4.2.189

[4] Centre for Disease Control (2013) Incidence and Trends of Infection with Pathogens Transmitted Commonly through Food-Foodborne Disease Active Surveillance Network, 10 US Sites 1996-2012. Morbidity and Mortality Weekly Report, 62, 283 287.

[5] Bezian, M.C., Ribou, G., Barberis-Giletti, C. and Megraud, F. (1990) Isolation of a 
Urease Positive Thermophilic Variant of Campylobacter lari from a Patient with Urinary Tract Infection. European Journal of Clinical Microbiology and Infectious Disease, 9, 895-897. https://doi.org/10.1007/BF01967506

[6] Belanger, A.E. and Shryock, T.R. (2007) Macrolide-Resistant Campylobacter: The Meat of the Matter. Journal of Antimicrobial Chemotherapy, 60, 715-723. https://doi.org/10.1093/jac/dkm300

[7] Lehtopolku, M. (2011) Antimicrobial Resistance in Campylobacter jejuni and Campylobacter coli. Department of Internal Medicine and Medical Microbiology and Immunology, University of Turku, Turku, Finland and the Antimicrobial Resistance Unit, National Institute for Health and Welfare (Former National Public Health Institute, KT4, Yurku, Finland ISBN, 978-951-4718-8).

[8] Wieczorek, K. and Osek, J. (2013) Antimicrobial Resistance Mechanisms among Campylobacter. BioMed Research International, 2013, Article ID: 340605.

https://doi.org/10.1155/2013/340605

[9] Salihu, M.D., Junaidu, A.U., Magaji, A.A. and Yakubu, Y. (2012) Prevalence and Antimicrobial Resistance of Thermophilic Campylobacter Isolates from Commercial Broiler Flocks in Sokoto, Nigeria. Research Journal of Veterinary Sciences, 5, 51-58. https://doi.org/10.3923/rjvs.2012.51.58

[10] Girgis, S.A., Rashad, S.S., Othman, H.B., Bassim, H.H., Kassem, N.N. and. El-Sayed, F.M. (2014) Multiplex PCR for Identification and Differentiation of Campylobacter Species and Their Antimicrobial Susceptibility Pattern in Egyptian Patients. International Journal of Current Microbiology and Applied Sciences, 3, 861-875.

[11] Ghana News Agency (2003) Hand Washing with Soap Could Prevent Death. Ghana News Agency, Accra.

[12] Clinical and Laboratory Standards Institute (2006) Methods for Antimicrobial Dilution and Disk Susceptibility Testing of Infrequently Isolated Bacteria. Approved Guideline M45-A, CLSI, Wayne.

[13] Coker, A.O., Isokpehi, R.D., Thomas, B.N., Amisu, K.O. and Obi, C.L. (2002) Human Campylobacteriosis in Developing Countries. Emerging Infectious Disease, 8, 237-244. https://doi.org/10.3201/eid0803.010233

[14] Coker, A.O. and Adefeso, A.O. (1994) The Changing Patterns of Campylobacter jejuni C. coli in Lagos, Nigeria after Ten Years. East African Medical Journal, 74, Article ID: 437440.

[15] Lindblom, G.B., Ahren, C., Changalucha, J., Gabone, R., Kaijser, B., Nilsson, L.A., et al. (1995) Campylobacter jejunil coli and Enterotoxigenic Escherichia coli (ETEC) in Faeces from Children and Adults in Tanzania. Journal of Infectious Diseases, 27, 589-593.

[16] Wren, B.W., Linton, D., Dorrell, N. and Karlyshev, A.V. (2001) Post Genome Analysis of Campylobacter jejuni. Journal of Applied Microbiology, 90, 36S-44S. https://doi.org/10.1046/j.1365-2672.2001.01352.x

[17] David, N.T., Martin, J.B., Peter, E.P., Bodhidatta, L. and Wang, W.L.L. (1987) Erythromycin Resistant Campylobacter Infections in Thailand. Antimicrobial Agents Chemotherapy, 31, 438-442. https://doi.org/10.1128/AAC.31.3.438

[18] Ashraful, H. and Rahman, K.M. (1991) Campylobacter jejuni as a Cause of Acute Diarrhea in Children: A Study of an Urban Hospital in Bangladesh. Journal of Tropical Medicine and Hygiene, 94, 50-54.

[19] Simango, C. and Nyahanana, M. (1997) Campylobacter enteritis in Children in an Urban Community. Central African Medical Journal, 43, 172-175.

[20] Abraham, C.A., Agbodaze, D., Nakanot, A., Fari, A. and Longmatey, H.E.K. (1990) 
Prevalence and Antibiogram of Campylobacter jejuni in Domestic Animals in Rural Ghana. Archives of Environmental Health, 45, 59-62. https://doi.org/10.1080/00039896.1990.9935926

[21] Samuel, S.O., Aboderin, A.O., Akanbi, A.A., Adegboro, B., Smith, S.I. and Coker, A.O. (2006) Campylobacter enteritis in Ilorin, Nigeria. East African Medical Journal, 83, 478-484.

[22] Lengerh, A., Moges, F., Unakal, C. and Anagaw, B. (2013) Prevalence, Associated Risk Factors and Antimicrobial Susceptibility Pattern of Campylobacter Species among under Five Diarrhoeagenic Children at Gondar University Hospital, Northwest Ethiopia. BMC Pediatrics, 13, 82. https://doi.org/10.1186/1471-2431-13-82

[23] Friedman, C.R., Niemann, J., Wegener, H.C. and Tauxe, R.V. (2000) Epidemiology of Campylobacter jejuni Infections in the United States and Other Industrialised Nations. In: Nachampkin, I. and Blaser, M.J., Eds., Campylobacte, ASM Press, Washington DC, 121-138.

[24] Fitzgerald, C., Patrick, M., Jerris, R., Watson, R., Tobin-D’Angelo, M., Gonzalez, A., Polage, C., Wymore, K., Gillim-Ross, L., Sadlowski, J., Monahan, J., Hurd, S., Dahlberg, S., De Martino, M., Pentella, M., Razeq, J., Leonard, C., Jung, C., Juni, B., Robinson, T., Gittelman, R., Garrigan, C. and Nachamkin, I., Campylobacter Diagnostics Working Group (2011) Multicenter Study to Evaluate Diagnostic Methods for Detection and Isolation of Campylobacter from Stool. Annual Meeting of the American Society for Microbiology, New Orleans, 20 September 2011.

[25] Gillespie, I.A., O’Brien, S.J., Frost, J.A., Tam, C., Tompkins, D., Neal, K.R., et al. (2006) The Campylobacter Sentinel Surveillance Scheme Collaborators. Investigating Vomiting and/or Bloody Diarrhea in Campylobacter jejuni Infection. Journal of Medical Microbiology, 55, Article ID: 741746. https://doi.org/10.1099/jmm.0.46422-0

[26] Mshana, S.E., Joloba, M.L., Kakooza, A. and Kaddu-Mulindwa, D. (2009) Campylobacter spp. among Children with Acute Diarrhea Attending Mulago Hospital in Kampala-Uganda. African Health Sciences, 9, 201-205.

[27] Megraud, F., Chevrier, D., Desplaces, N., Sedallian, A. and Guesdon, J.L. (1988) Urease-Positive Thermophilic Campylobacter (Campylobacter laridis variant) Isolated from an Appendix and from Human Feces. Journal of Clinical Microbiology, 26, 1050-1051.

[28] Gibreel, A. and Taylor, D.E. (2006) Macrolide Resistance in Campylobacter jejuni and Campylobacter coli. Journal of Antimicrobial Chemotherapy, 58, 243-255. https://doi.org/10.1093/jac/dkl210

[29] Newman, M.J., Frimpong, E., Donkor, E.S., Opintan, J.A. and Asamoah-Adu, A. (2011) Resistance to Antimicrobial Drugs in Ghana. Infection and Drug Resistance, 4, 215-220.

[30] Fitzgerald, F., Whichard, J. and Nachamkin, I. (2008) Diagnosis and Antimicrobial Susceptibility of Campylobacter Species. In: Nachamkin, I., Szymanski, C.M. and Blaser, M.J., Eds., Campylobacter, American Society for Microbiology, Washington DC, 227-243.

[31] Luber, P., Wagner, J., Hahn, H. and Bartelt, E. (2003) Antimicrobial Resistance in Campylobacter jejuni and Campylobacter coli Strains Isolated in 1991 and 2001-2002 from Poultry and Humans in Berlin, Germany. Antimicrobial Agents and Chemotherapy, 47, 3825-3830. https://doi.org/10.1128/AAC.47.12.3825-3830.2003

[32] Prats, G., Mirelis, B., Llovet, T., Muñoz, C., Miro, A.E. and Navarro, F. (2000) Antibiotic Resistance Trends in Enteropathogenic Bacteria Isolated in 1985-87 and 
1995-98 in Barcelona. Antimicrobial Agents and Chemotherapy, 44, 1140-1145. https://doi.org/10.1128/AAC.44.5.1140-1145.2000

[33] Iovine, N.M. (2013) Resistance Mechanisms in Campylobacter jejuni. Virulence, 4, 230-240. https://doi.org/10.4161/viru.23753

[34] Turkson, P.K. (2008) Use of Drugs and Antibiotics in Ghana. Ghana Journal of Agric Science, 41, 23-33.

[35] Payot, S., Avrain, L., Magras, C., Praud, K., Cloeckaert, A. and Chaslus-Dancla, E. (2004) Relative Contribution of Target Gene Mutation and Efflux to Fluoroquinolone and Erythromycin Resistance, in French Poultry and Pig Isolates of Campylobacter coli. International Journal of Antimicrobial Agents, 23, 468-472.

https://doi.org/10.1016/j.ijantimicag.2003.12.008

[36] Chen, X., Naren, G.W., Wu, C.M., Wang, Y., Dai, L., Xia, L.N., et al. (2010) Prevalence and Antimicrobial Resistance of Campylobacter Isolates in Broilers from China. Veterinary Microbiology, 144, 133-139. https://doi.org/10.1016/j.vetmic.2009.12.035

[37] Shin, E. and Lee, Y. (2010) Characterization of Erythromycin-Resistant Porcine Isolates of Campylobacter coli. Microbial Drug Resistance, 16, 231-239. https://doi.org/10.1089/mdr.2010.0039

[38] Belongia, E. and Schwartz, B. (1998) Strategies for Promoting Judicious Use of Antibiotics by Doctors and Patients. Britain Medical Journal, 317, 668-671. https://doi.org/10.1136/bmj.317.7159.668

Submit or recommend next manuscript to SCIRP and we will provide best service for you:

Accepting pre-submission inquiries through Email, Facebook, LinkedIn, Twitter, etc. A wide selection of journals (inclusive of 9 subjects, more than 200 journals) Providing 24-hour high-quality service User-friendly online submission system Fair and swift peer-review system Efficient typesetting and proofreading procedure Display of the result of downloads and visits, as well as the number of cited articles Maximum dissemination of your research work

Submit your manuscript at: http://papersubmission.scirp.org/

Or contact ojmm@scirp.org 